\title{
Cantas pezas ten o crebacabezas? A corresponsabilidade no persoal docente e investigador da Universidade de Vigo
}

\author{
How many pieces does the puzzle have? Co-responsibility of the \\ academic staff working at the University of Vigo
}

Iria Vázquez Silva

Recibido: $10 / 07 / 2020$

Aceptado: 01/02/2021

\section{RESUME}

Neste artigo presentarei unha análise da corresponsabilidade entre a vida persoal, familiar e laboral do Persoal docente e investigador que traballa na Universidade de Vigo. A partir da explotación de 29 entrevistas en profundidade examinarei as necesidades e demandas detectadas no PDI no ámbito da corresponsabilidade, analizando o seu impacto na traxectoria profesional. $O$ asentamento da precariedade laboral na universidade, as xornadas vespertinas, a falla de transparencia na asignación de materias e horarios e a penalización da maternidade na carreira profesional son, a día de hoxe, algunhas das barreiras máis relevantes para acadar maiores cotas de corresponsabilidade e igualdade na Universidade de Vigo. Ademais, os recentes indicadores da nova realidade poscovid-19 indican un afondamento aínda maior nestas desigualdades de xénero.

Palabras clave: corresponsabilidade, coidados, persoal docente $e$ investigador, maternidade, precariedade, covid-19, universidade, xénero.

\section{RESUMEN}

En este artículo presentaré un análisis de la corresponsabilidad entre la vida personal, familiar y laboral del Persoal docente e investigador que trabaja en la Universidade de Vigo. A partir de la explotación de 29 entrevistas en profundidad examinaré las necesidades y demandas detectadas en el PDI en el ámbito de la corresponsabilidad, analizando su impacto en la trayectoria profesional. El asentamiento de la precariedad laboral en la universidad, las jornadas vespertinas, la falta de transparencia en la asignación de materias y horarios y la penalización de la maternidad en la carrera profesional son, a día de hoy, algunas de las barreras más relevantes para lograr mayores cuotas de

Iria Vázquez Silva é Profesora Axudante Doutora no Departamento de Socioloxía e Ciencia Política e da Administración e Filosofía da Universidade de Vigo e membro do Grupo de Estudos Territoriais (GET) da Universidade da Coruña. Correo electrónico: ivazquez@uvigo.es. ID: http://orcid.org/0000-0002-7702$\underline{0662}$

Cómo citar este artículo: Vázquez Silva, Iria (2020). Cantas pezas ten o crebacabezas? A corresponsabilidade no persoal docente e investigador da Universidade de Vigo. Atlánticas. Revista Internacional de Estudios Feministas, 5 (1), 30-58. doi: http: / / dx.doi.org/10.17979/ arief.2020.5.1.6820 
corresponsabilidad e igualdad en la Universidade de Vigo. Además, los recientes indicadores de la nueva realidad poscovid-19 indican una profundidad aún mayor en estas desigualdades de género.

Palabras clave: corresponsabilidad, cuidados, personal docente e investigador, maternidad, precariedad, covid-19, universidad, género.

\section{ABSTRACT}

In this paper I will present an analysis of the co-responsibility between the personal, family and work life of the academic staff working at the University of Vigo. On the basis of the exploitation of 29 in-depth interviews, I will examine the needs and demands about co-responsibility detected in the academic staff, analyzing its impact on the professional trajectory. The establishment of precarious work in the university, the evening sessions, the lack of transparency to assign subjects and schedules and the penalization of motherhood in the professional career are, today, some of the most relevant barriers to achieving greater levels of co-responsibility and equality in University of Vigo. In addition, recent indicators of the new reality Poscovid-19 indicate an even greater deepening in these gender inequalities.

Keywords: Co-responsibility, care, motherhood, academic staff, gender, precarious work, Covid-19, university, gender. 


\section{INTRODUCCIÓN}

Neste artigo analizarei algunhas das demandas máis relevantes recollidas entre o persoal docente e investigador (en adiante PDI) da Universidade de Vigo con respecto a corresponsabilidade. En concreto, incluirei na análise a aquelas persoas vinculadas por contrato ou por nomeamento coa UVigo, incorporando tanto ao persoal docente funcionario como laboral, así como persoal investigador contratado con cargo a proxectos.

Os obxectivos fundamentais deste artigo son dous: por unha banda, examinar as necesidades e demandas que posúe o PDI da UVigo sobre a conciliación da súa propia vida persoal coa vida laboral (académica) e familiar; e pola outra banda, analizar o impacto que posúe a "fenda de coidados" na carreira académica do persoal docente e investigador. Así mesmo, para cumplimentar ambos obxectivos prestarei unha especial atención ás figuras laborais máis precarias e incorporando unha ollada comparativa entre homes e mulleres. Por último, farase alusión ao impacto recente da pandemia nesta realidade.

É claro que na actualidade as Universidades posúen unha cantidade de figuras PDI que complexizan a análise. Unha diversidade de categorías que perpetúa a desigualdade no PDI, onde temos profesorado que vai desde as categorías máis precarias como convidada, asociada ou interina (todas formas a tempo parcial nesta Universidade) até figuras estabilizadas e funcionarias como son as titulares ou catedráticas. Ademais, a UVigo posúe, como moitas outras universidades, unha forte segregación horizontal e vertical en función do xénero (Xarxas vives, 2019). No seu portal de transparencia, con data 31/12/2019, recóllese que hai 1477 persoas PDI, o 41,6\% son mulleres. Dese total de persoal, o 51,9\% é funcionario; porén, as mulleres están infrarrepresentadas como funcionarias, só son o 36,8\% delas, cinco puntos por debaixo da súa presencia na UVigo, mentres aúnan o 46,8\% do persoal laboral.

No documento "Informe de datos da composición de mulleres e homes na Universidade de Vigo, 2009-2014" (2015) aloxado na páxina institucional da Unidade de Igualdade, pódese constatar que as mulleres son máis numerosas nas categorías laborais inferiores (con contratos temporais e a tempo parcial), e máis escasas nas categorías laborais máis estables e elevadas. Por exemplo, no periodo 2009-2014, as mulleres son só o 38,6\% das titulares, mentres son o 
$52,5 \%$ de axudantes doutoras ou o $66,6 \%$ de interinas. Dado este contexto precisamos realizar análises capaces de captar as dificultades de corresponsabilidade en colectivos tan dispares, e onde o precariado (Standing, 2013) comeza a asentarse entre o PDI máis novo e cunha maior incidencia nas mulleres.

Este artigo apoiarase no traballo de campo realizado para tres proxectos de investigación financiados todos pola Unidade de Igualdade da Universidade de Vigo.

A estrutura do artigo é a que sigue: en primeiro lugar, se realizará unha contextualización conceptual de traballo de coidados, conciliación e corresponsabilidade; posteriormente detallarase a metodoloxía e técnicas empregadas para presentar por despois os resultados acadados. A recollida de información chega ata o ano 2020, coa explotación dunha recente enquisa realizada pola UVigo, detallando o impacto que está a ter a Covid-19 no PDI no eido da conciliación.

\section{A UTOPÍA MÍDESE EN MINUTOS?}

Desde a explosión da segunda onda do movemento feminista levamos xa un longo percorrido na visibilización do traballo doméstico, reproductivo e de coidados.

Nesta contextualización teórica non pretendo facer unha recollida pormenorizada de todo o desenvolvemento teórico ao redor dos conceptos de traballo doméstico, reproductivo e de coidados'; senón, máis ben, trazar un breve marco xeral sobre estes conceptos.

É nos anos 1970 cando xerminan as discusións en torno ao traballo non remunerado. $\mathrm{O}$ persoal vóltase político e o que acontece nos fogares, por fin, deixa de ser invisíbel. Foi moi intenso o coñecido como o debate sobre o traballo doméstico (DTD) impulsado eses anos polas pensadoras feministas. Unha das autoras fundamentais é Christine Delphy. Coa publicación en 1970 de L'ennemi principal vai introducir o concepto da "autonomía absoluta" que expón que a

- Para ese menester, consultar o excelente libro editado por Cristina Carrasco, Cristina Borderías e Teresa Torns (2011). 
opresión das mulleres emerxe das relacións patriarcais de poder imperantes na familia e no sistema político, así como no eido das relacións sociais de produción (Benería, 1979).

Na década de 1980 comeza a falarse do "traballo de coidados", ou o que as sociólogas italianas denominan o "lavoro di cura" (por exemplo Balbo, 1982; Saraceno, 1980). Paralelamente, autoras anglosaxonas (Finch e Groves, 1983) desenvolven o "care" que foi o que posteriormente alcanzou maior recoñecemento, e na década de 1990 multiplícanse as publicacións sobre os coidados. Unha das autoras a destacar é Folbre (1995), quen chegou ao argumento de que "o traballo de coidados está devaluado sinxelamente porque é un traballo que realizan as mulleres".

No estado español, é sobre todo a partir da década de 2000 cando se multiplican publicacións sobre esta cuestión desde unha perspectiva feminista. Moitos destes traballos examinan a relación entre o Estado de Benestar e o traballo de coidados (ver Pérez- Caramés, 2010). Como recolle esta autora, as investigadoras en materia de xénero e políticas públicas criticaron o famoso esquema proposto por Esping-Andersen (1993), remarcando a cegueira de dito esquema ante o feito de que a "variable xénero atravesa e fragmenta os diferentes rexímenes do Estado de Benestar" (Pérez-Caramés, 2010:125). Hai que ter en conta que o traballo doméstico e dos fogares se satisface a partir dunha ou varias das seguintes vías: o traballo non remunerado, o mercado e o sector público (Carrasco, 2006).

Comezaremos polo primeiro punto, o traballo non remunerado. As mulleres dentro dos fogares realizan a maioría do traballo doméstico e tamén actividades afectivas que implican coidados directos ás persoas e que se prestan no entorno familiar de modo gratuito. A última Enquisa de emprego do tempo en España segue mostrando grandes diferenzas por xénero. Así, sendo unha media das persoas enquisadas, o tempo que as mulleres dedican ao fogar e aos coidados familiares segue sendo en 2010, dúas horas e cuarto máis que os varóns. Se ben houbo un lixeiro cambio desde 2003, aumentando os varóns 20 minutos a súa dedicación a estas tarefas reproductivas. 
E ben, visto este paronama, e a pesares da cantidade de tempo non remunerado que empregan as mulleres nos fogares, non sempre chega. Os homes non dan asumido o traballo non remunerado que lles toca, e o sistema de cobertura social dos coidados no contexto español é nimio: a ecuación do tempo segue sen sair. Entón, é cando se acode de xeito xeralizado á contratación de traballadoras que se dedican ás tarefas domésticas e ao coidado de persoas no fogar.

Por último, atópase o sector público. O Estado de Benestar español caracterízase por seguir un modelo asistencial, parcialmente privatizado e/ou externalizado, que ofrece certo nivel de cobertura pero cunha protección de baixa intensidade (Moreno, 2002; Sapir, 2005).

Visto este esquema, queda claro que son os fogares (e no seu interior, as mulleres) as que acaban axustando o desaguisado dun sistema capitalista e patriarcal que desprecian o sostemento da vida, e operan nun contexto cun ausente sistema público de coidados.

\section{AS PEZAS DO CREBACABEZAS. DA CONCILIACIÓN Á CORRESPONSABILIDADE}

Logo deste breve percorrido, xa estamos en condicións de entrar a definir os coidados, a conciliación e a corresponsabilidade.

Que son os coidados? Seguindo a Amaia Pérez (2006:10) por coidados podemos entender a xestión e o mantemento cotiá da vida e da saúde. Presenta unha dobre dimensión "material", corporal -realizar tarefas concretas con resultados tanxibles, atender ao corpo e as súas necesidades fisiolóxicas- e "inmaterial", afectivo-relacional -relativa ao benestar emocional.

Os estudos de xénero levan máis dunha década a falar da "crise dos coidados": unha crise que se da tanto se os coidados son remunerados (as empregadas do fogar, a axuda a domicilio, traballadoras de residencias, de escolas infantís, etc.) como se non son remunerados (dentro da familia, das asociacións, colectivos, etc.). En ambos casos detéctanse dous elementos comúns: son desvalorizados 
económica e socialmente; ao tempo que son realizados, na súa maioría, por mulleres.

O certo é que reducir a vida das persoas ao binomio traballo- familia é tan perigoso como inxusto coa realidade. Toda persoa precisa, máis alá do traballo remunerado e da familia, un tempo e un espazo propio para disfrutar da súa dimensión social e persoal (Blahopoulou, 2015:23-24). É por iso que a literatura actual entende a conciliación engadindo máis eidos, definíndoa como o equilibrio entre a vida laboral, familiar e persoal e incorporando tamén as relacións afectivas, as responsabilidades familiares, o ocio e o tempo libre para o desenvolvemento persoal, así como o tempo dedicado a actividades sociais, voluntariado, etc. É polo tanto un eixe fundamental para todas as persoas, e non só para aquelas que teñan crianzas ou outras persoas dependentes a cargo.

Como se recolle na publicación do Instituto da Muller dirixida por Rivero (2008:86) "o amplo uso mediático e político do termo conciliación ten contribuido a baleirar o seu contido, a debilitar o seu significado. Tal ver por iso, últimamente asistimos á emerxencia e difusión dun novo termo, acaso máis expresivo que o de conciliación: referímonos á noción de corresponsabilidade". Este termo fai alusión ao reparto igualitario de tarefas e responsabilidades familiares entre todas as persoas que conviven en familia. $\mathrm{O}$ interesante deste enfoque é que pon de manifesto que para lograr ese "equilibrio" entre a vida laboral, familiar e persoal é precisa a distribución equilibrada dentro do fogar das tarefas domésticas e de coidados, co fin de distribuir xustamente os tempos de vida de homes e mulleres.

Neste senso, a corresponsabilidade apuntaría a un novo pacto social que incorpora tres dimensións (Casado e Gómez, 2006): 1. A corresponsabilidade entre diferentes axentes sociais, como o Estado, sindicatos, empresas, ONGs, insitutucións, etc. 2. A nomeada corresposabilidade entre varóns e mulleres, que debe subvertir os roles tradicionais de xénero e de distribución dos tempos, e 3. Entre os diferentes membros da familia, desde unha ollada interxeracional que alude á responsabilización colectiva no sostemento económico-afectivo do fogar. 
No noso contexto, desde fai unha década está facéndose un especial énfase na denominada "crise dos coidados", como unha das crises ás que nos temos que enfrontar como sociedade; e que nos obriga (tarde ou temprano) a replantexar a economía poñendo a vida no centro, o cal supón repensar a división entre a economía monetarizada e a non monetarizada, rexeitando tamén o individualismo económico (Pérez, 2006).

Por último, mencionarei a modo de contexto o marco normativo, onde temos como referencia a nivel estatal a Lei Orgánica 3/2007 do 22 de marzo, para a igualdade efectiva de mulleres e homes. Esta lei, no Título V regula o principio de igualdade no emprego público. Neste eido, o artigo 51 establece os criterios de actuación das Administracións públicas dispoñendo que "as Administracións públicas, no ámbito das súas respectivas competencias e en aplicación do principio de igualdade entre mulleres e homes, "deberán remover os obstáculos que impliquen a pervivencia de calquera tipo de discriminación co fin de ofrecer condicións de igualdade efectiva entre mulleres e homes no acceso ao emprego público e no desenvolvemento da carreira profesional"; así como "facilitar a conciliación da vida persoal, familiar e laboral, sen menoscabo da promoción profesional".

\section{ESTRATEXIA METODOLÓXICA}

Neste artigo explotarei fundamentalmente o traballo de campo realizado nun recente proxecto (eliminación da referencia por motivos de anonimato, 2019). De xeito complementario, empregarei o traballo de campo realizado para (eliminación de referencia por motivos de anonimato, 2015). Logo de presentar estes resultados cualitativos (anteriores á pandemia), serán introducidas as principais conclusións da enquisa realizada en 2020 a PDI da UVigo, analizando específicamente o impacto da pandemia na conciliación e na produción científica dos e das académicas / os (eliminación de referencia por anonimato).

O proxecto realizado en 2015 analiza a traxectoria das mulleres docentes na Universidade de Vigo, e posúe un apartado específico sobre conciliación. Neste estudo concluíuse que era preciso incorporar na análise aos homes docentes para poder realizar un achegamento comparativo. Deste xeito, o proxecto máis 
recente incorpora homes na súa análise e se centra exclusivamente no eido da corresponsabilidade. En ambos casos, a metodoloxía foi cualitativa a través de entrevistas en profundidade, dado o carácter persoal das temáticas a tratar. Todas as entrevistas realizadas foron gravadas.

Táboa 1. Resumo das entrevistas realizadas (2019)

\begin{tabular}{|c|c|c|}
\hline $\begin{array}{l}\text { Campus de } \\
\text { Vigo }\end{array}$ & Campus de Ourense & Campus de Pontevedra \\
\hline $\begin{array}{l}\text { E1: Muller, Contratada } \\
\text { Posdoutoral, vive con } \\
\text { parella e filla (30-34 anos) }{ }^{2} .\end{array}$ & $\begin{array}{l}\text { E6: Home, Axudante } \\
\text { Doutor, vive só (35- } 39 \\
\text { anos). }\end{array}$ & $\begin{array}{l}\text { E9: Muller, Contratada } \\
\text { Doutora, vive con parella } \\
\text { (50-54 anos). }\end{array}$ \\
\hline $\begin{array}{l}\text { E2: Home, Catedrático, } \\
\text { vive con parella e fillo/as } \\
\text { (50-54 anos). }\end{array}$ & $\begin{array}{l}\text { E7: Muller, Asociada, vive } \\
\text { soa ( } 50-54 \text { anos). }\end{array}$ & \\
\hline $\begin{array}{l}\text { E3: Home, Contratado } \\
\text { posdoutoral, anos, vive } \\
\text { con parella (35-39 anos). }\end{array}$ & $\begin{array}{l}\text { E8: Muller, Contratada } \\
\text { Doutora, vive con parella } \\
\text { e fillo/as. Docencia en } \\
\text { Vigo e Ourense (45-49 } \\
\text { anos). }\end{array}$ & \\
\hline $\begin{array}{l}\text { E4: Muller, Contratada } \\
\text { Predoutoral, vive con } \\
\text { parella e fillo (35-39 anos). } \\
\text { E5: Muller, Contratada } \\
\text { con cargo a proxecto, vive } \\
\text { coa parella (40-44 anos). }\end{array}$ & & \\
\hline
\end{tabular}

Fonte: elaboración propia a partir do traballo de campo

No marco do traballo de campo realizado en 2019 leváronse a cabo nove entrevistas en profundidade. A selección das persoas entrevistadas e a contactación foi, por unha banda, a través da propia Unidade de Igualdade, xa que este servizo recibiu diferentes escritos por parte fundamentalmente de PDI expresando unha serie de necesidades vinculadas á conciliación. Os seus contactos foron retomados para a realización das entrevistas. A partir delas e a través da coñecida "bola de neve" (novos contactos froito das primeiras entrevistas), fun achegándome a outros perfís de interese, tratando que - Para asegurar o anonimato das persoas entrevistadas, só se proporcionan os intervalos de idade das
persoas entrevistadas. 
estiveran presentes diferentes figuras de PDI (desde persoal investigador, a profesorado con distintas categorías profesionais).

Por outra banda, o traballo de campo desenvolvido en 2015 foi colectivo, realizado polo conxunto do equipo de investigación. En total realizáronse 20 entrevistas, seleccionadas en base a diferentes categorías e eidos de coñecemento do PDI (de importancia para analizar as traxectorias profesionais).

Táboa 2. Resumo das entrevistas realizadas (2015)

\begin{tabular}{|c|c|c|}
\hline $\begin{array}{l}\text { Campus de } \\
\text { Vigo }\end{array}$ & Campus de Ourense & Campus de Pontevedra \\
\hline $\begin{array}{l}\text { E10: Muller, Titular, eido } \\
\text { científico (50-54 anos). }\end{array}$ & $\begin{array}{l}\text { E16: Muller, Titular, eido } \\
\text { tecnolóxico (55-59 anos). }\end{array}$ & $\begin{array}{l}\text { E25: Muller, Contrada Doutora, } \\
\text { eido xurídico-social ( } 40-44 \text { anos). }\end{array}$ \\
\hline $\begin{array}{l}\text { E11: Muller, Titular, eido } \\
\text { tecnoloxíco (45-49 anos). }\end{array}$ & $\begin{array}{l}\text { E17: Muller, Contratada } \\
\text { Doutora, eido xurídico-social } \\
\text { (45-49 anos). }\end{array}$ & $\begin{array}{l}\text { E26: Muller, Axudante Doutora, } \\
\text { eido xurídico-social (40-44 anos). }\end{array}$ \\
\hline $\begin{array}{l}\text { E12: Muller, Titular, eido } \\
\text { científico (55-59 anos). }\end{array}$ & $\begin{array}{l}\text { E18: Muller, Asociada, eido } \\
\text { xurídico-social (50-54 anos). }\end{array}$ & $\begin{array}{l}\text { E27: Muller, Catedrática, eido } \\
\text { xurídico-social (50-54 anos). }\end{array}$ \\
\hline $\begin{array}{l}\text { E13: Muller, Titular, eido } \\
\text { científico (55-59 anos). }\end{array}$ & $\begin{array}{l}\text { E19: Muller, Contratada } \\
\text { Doutora, eido xurídico- social } \\
\text { (40-44 anos). }\end{array}$ & $\begin{array}{l}\text { E28: Muller, Catedrática, eido } \\
\text { Artes e Humanidades (55-59 } \\
\text { anos). }\end{array}$ \\
\hline $\begin{array}{l}\text { E14: Muller, Catedrática, eido } \\
\text { científico ( } 55-59 \text { anos). }\end{array}$ & $\begin{array}{l}\text { E20: Muller, Titular, eido } \\
\text { xurídico-social (50- } 54 \text { anos). }\end{array}$ & $\begin{array}{l}\text { E29: Muller, Asociada, eido } \\
\text { xurídico-social (35-39 anos). }\end{array}$ \\
\hline $\begin{array}{l}\text { E15: Muller, } \\
\text { Doutora, eido Artes e } \\
\text { Humanidades (45-49 anos). }\end{array}$ & $\begin{array}{l}\text { E21: Muller, Titular, eido } \\
\text { científico (45-49 anos). }\end{array}$ & \\
\hline & $\begin{array}{l}\text { E22: Muller, Titular, eido } \\
\text { tecnolóxico (45-49 anos). }\end{array}$ & \\
\hline & $\begin{array}{l}\text { E23: Muller, Contratada } \\
\text { Doutora, eido tecnolóxico (40-45 } \\
\text { anos). }\end{array}$ & \\
\hline & $\begin{array}{l}\text { E24: Muller, Catedrática eido } \\
\text { científico ( } 45-49 \text { anos). }\end{array}$ & \\
\hline
\end{tabular}

Fonte: elaboración propia a partir do traballo de campo 
Así mesmo, e para captar o impacto da pandemia da Covid-19, se explotarán algúns dos resultados dunha enquisa realizada a PDI da UVigo entre xullo e setembro de 2020. Esta enquisa foi levada a cabo no marco do proxecto (omisión por anonimato) e conta cunha mostra de 275 cuestionarios, cunha maior taxa de resposta entre as mulleres (54\%) que entre os homes $(46 \%)^{3}$. A través da enquisa levouse a cabo un seguimento da produción científica realizada por mulleres académicas e investigadoras da UVigo, antes e durante da Covid-19, cunha especial atención á medición do traballo de coidados e o impacto da pandemia no mesmo.

\section{XORNADAS VESPERTINAS E DISPOÑIBILIDADE CONTINUA: O "PRECARIADO" ASÉNTASE NA UNIVERSIDADE}

No traballo de campo cualitativo, o primeiro dos resultados a destacar é que unha das necesidades máis repetidas nas voces do/as informantes ten que ver coa ordenación da xornada laboral e a falla de transparencia na asignación de materias e horarios no PDI.

Logo dunha longa carreira docente, un dos entrevistados salienta a importancia de incrementar a transparencia e a rendición de contas con respecto aos horarios docentes e a selección de materias para impartir por parte do profesorado. Este Catedrático fai alusión á importancia de xerar unha normativa clara con respecto á selección da docencia que se imparte e dos horarios lectivos; unha transparencia que debería poñer no centro a corresponsabilidade entre a vida laboral, familiar e persoal. A investigación levada a cabo detectou unha necesidade de replantexar unha normativa común para todos os departamentos onde se dea prioridade ás persoas con responsabilidades familiares de coidado para a selección de horarios docentes dun xeito obrigatorio.

"Hai un discurso formal e un discurso real, o discurso formal é o discurso da adaptacion da xornada e tal, eu son bastante pesimista porque o que me di a historia é que toda a Universidade é moi medieval, todo isto de axustes

\footnotetext{
A enquisa realizada a unha mostra do PDI da universidade indica unha serie de datos de caracterización básica das persoas enquisadas atendendo ao sexo, idade, tipo de fogar e coidados de fillas ou fillos menores de 12 anos.
} 
horarios, eu vexo moi pouca marxe de mellora, eh... quen elixe primeiro a docencia? Hai unha norma que elixa primeiro a persoa que teña fillos ao seu cargo, esa norma como se executa? É dicir, a ver aquí me tratan como un príncipe: a ver escolle tu a docencia, eso non pode ser así, digamos que hai unha serie de malos hábitos, a min me parece que todo isto vai por dúas cousas, transparencia e rendición de contas... nesta Universidade, isto me parece esencial. A norma pode existir, a min me parece elemental, que se dean prioridades a xente que ten máis necesidades (...), conta a idade dos fillos, conta o entorno familiar, e moitas veces pertence á privacidade, conta a capacidade económica, entón... pero básicamente o que hai é unha mala transparencia e unha mala rendición de contas, por exemplo, o criterio que se seguiu masivamente nesta facultade é a xerarquía de antigüidade, que é o que realmente se sigue, estámolo recoñecendo? (...) (E2: Home Catedrático)‘.

Acerca dos horarios docentes, hai que sinalar que as figuras docentes máis precarias (profesorado convidado, asociado e interino) deberían, segundo os/as informantes, ter máis voz na selección horaria. Estas figuras conforman o "precariado universitario", cunhas lamentábeis condicións laborais (temporalidade, parcialidade, peores horarios e salarios, etc.) e con escaso poder na toma de decisións ao interior dos departamentos universtiarios. Como sinala Díez (2017) a contratación de figuras cada vez máis temporais, precarias e con dereitos cada vez máis recortados, a fin de reducir costes laborais e incrementar o servilismo laboral, forma parte do asalto neoliberal aos servizos públicos. É nese precariado universitario, onde as mulleres PDI están sobre-representadas con respecto aos varóns.

Neste senso, tal e como sinalaron diferentes informantes, a racionalización dos horarios nos centros é unha medida urxente a implementar. É dicir, os horarios docentes até as 21,30 horas resultan excesivos se queremos traballar por unhas xornadas laborais que permitan a corresponsabilidade. Isto tamén afecta, por suposto, aos horarios de peche dos centros, e polo tanto á xornada laboral do PAS na quenda de tarde. O peche de centros debería unificarse ao redor das 19,30 horas, unha hora límite máis axeitada.

\footnotetext{
${ }^{4}$ Os fragmentos de entrevistas serán reproducidos na lingua orixinal falada pola persoa entrevistada (galego ou español).
} 
Outra das cuestións claves con respecto á xornada, ten que ver co perigo da dispoñibilidade continua do persoal docente e investigador. Hai que ter en conta que a carreira docente e investigadora posúe na actualidade a "particulariedade" dunha estabilización moi tardía, e cunha grande intensidade horaria nas tarefas docentes e investigadoras nas figuras máis precarias (convidadas, interinas): precísase nesa etapa construir un currículum vitae competitivo para a posíbel consolidación futura, cuns méritos baseados no maior volume de docencia, participación en proxectos e publicacións posíbeis.

Certamente, no caso do profesorado, existe unha diversidade de casuísticas en función da categoría que se posúa, da intensidade da carreira investigadora e da responsabilidade en cargos de xestión. Por exemplo, un dos nosos informantes, Axudante Doutor, salienta a súa dificultade na coordinación horaria da xestión administrativa, a investigación e a docencia. El vive só e non ten crianzas nin persoas dependentes ao seu cargo, pero si salienta que a intensidade da súa xornada fixo que deixara de "prestar" axudas puntuais de apoio familiar como acompañamentos médicos. Outro dos aspectos que se reflexa no seu discurso é a obriga de "recuperar" as horas que se empregan para días de asuntos propios, e que dalgún xeito, imposibilitan exercer este dereito dun xeito completo.

“Moito menos ocio, pois son cuestión que tu deixas de prestar, en plan... acompañamentos médicos, e que podas ter con familiares, e que poidas ir, esto é un pouco, sona mal decilo pero, eu na Xunta tiña un día de asuntos propios e ese día non traballaba, tiña dereito a iso, aquí tu tes dereito, buscas un compañeiro que te cubra e que che firme esas horas, pero se hoxe che cubre un compañeiro, mañá tes que cubrilo a el, co cal che supón un sobreesforzo, cando na Xunta un día de asuntos propios é un día de asuntos propios" (E6: Home, Axudante Doutor).

Por outra banda, a dispoñibilidade horaria continuada é outro dos ámbitos especialmente preocupante para moito persoal docente e investigador. Os periodos vacacionais e as fines de semana non sempre son respectadas. Este mesmo informante, anteriormente traballador na Xunta de Galicia, realiza unha comparativa con respecto as súas condicións laborais e específicamente respecto á xornada laboral hiperconectada. 
"Ao mellor tampouco podo comparar moito, fago unha comparativa entre isto e a administración pública, nunca traballei na privada, e non sei... na Xunta eu sabía que te ías de vacacións e non che ía chamar ninguén, aquí te chaman dende secretaría por cuestións de traballo, é dicir, que nin sequera podes desconectar no mes de vacacións, nin na fin de semana, mandanche un mail na fin de semana, todo o mundo está conectado, o sea que prácticamente non desconectas en ningún momento, como unha cobertura case permanente de dispoñibilidade permanete, mañá, tarde e... (E6: Home, Axudante doutor).

Para desenvolver e mellorar a corresponsabilidade entre a vida laboral e persoal é imprescindíbel acotar esa "demanda de dispoñibilidade sen límites" presentes en moitas xornadas laborais que nunca rematan, dado que desde a "casa" seguimos conectados/as (Blahopoulou, 2015:36). Unha das informantes, profesora Contratada Doutora (E9) conclúe nesta liña que sería necesario un "apagón de correos electrónicos" na fin de semana e nas vacacións, onde continúan chegando correos de alumnado para titorías ou outros temas relacionados coa docencia ou a investigación por parte das institucións académicas.

\section{6. Ás VOLTAS COA "FOLGA DE VENTRES"?}

\subsection{A necesidade de despenalizar a $\mathrm{m}(\mathrm{p})$ aternidade na carreira investigadora}

No eido da carreira docente e investigadora, todas as persoas PDI entrevistadas e que teñen fillos/as fixeron unha alusión explítica á dificultade de conciliación da m(p)aternidade coa carreira investigadora. Incluirei aos homes na análise, aínda que como sabemos, a intensidade en horas de coidado ás crianzas continúa sendo maioritariamente feminina, o que se verá reflexado en moitos discursos das nosas informantes.

\footnotetext{
${ }^{5}$ A "folga de ventres" foi proclamada en Francia por Nelly Roussel en 1904 como unha reivindicación das medidas anticonceptivas, abogando tamén por un "salario de maternidade" para a dedicación persoal aos seus fillo/as das mulleres que así o desexaran (Bock, 1993:445). En xeral, este concepto enténdese no contexto neomalthusiano, como unha negativa a procrear como unha arma de resistencia ao capitalismo. O título deste apartado quere xogar con este concepto, aínda que, como veremos, focalizándose na penalización que ten o exercicio da maternidade no contexto académico.
} 
A intensidade investigadora, a dificultade de conciliar proxectos de investigación coa $\mathrm{m}(\mathrm{p})$ aternidade, a esixencia dos sexenios "vivos" e os problemas derivados de realizar estadías longas no estranxeiro foron algúns dos temas clave que veremos neste apartado.

En primeiro lugar, tres das nosas informantes salientaron a dificultade de conciliar a m(p)aternidade con traballar con cargo a proxectos de investigación. O problema fundamental ten que ver con que nos grandes proxectos de investigación non está contemplada a prórroga se algunha persoa do equipo investigador solicita unha baixa por maternidade ou paternidade. Certamente, hai proxectos nos que existe a posibilidade dunha prórroga, pero únicamente aplica para o/a investigador/a principal (I.P), e non para o caso de que outra persoa do equipo investigador teña crianzas. A seguinte entrevistada relata as dificultades que tivo que afrontar no último mes de embarazo mentres estaba contratada con cargo a un proxecto estatal, dada a ausencia de prórroga polo seu embarazo.

\footnotetext{
“Lo que me pasó a mi, mi contrato estaba en un proyecto del Ministerio, que empezó antes de que yo me uniese, entonces yo tenía que hacer un experimento, embarazada de ocho meses y pico, hasta tres semanas antes de dar a luz, haciendo un experimento que duró un mes, y trabajando todos los días, o lo hacía o no se hacía, porque el proyecto no se paraba, no tenía tiempo para hacerlo después" (E4: Muller, Contratada Predoutoral).
}

Outro investigador salienta na mesma liña, que o feito de ser nai ou pai choca co ideal de "investigador/a" que se fomenta desde a maioría dos proxectos de investigación. A cuestión clave novamente é a necesidade de prórrogas para poder completar os resultados de investigación.

"Que vayas a ser padre o madre es un problema del sistema, y más en el mundo de investigación en el que se centra por proyectos (...), le dan un proyecto a tu 
jefe, te puede contratar, pero vas a ser padre o madre, ¿cómo hace esa persona investigadora para contratarte si no vas a poder trabajar? Te contrata, te dan la baja, muy bien, es un permiso, el dinero vuelve al proyecto... pero ese trabajo no se consigue hacer, o tienen que contratar a otra persona para que haga ese trabajo, que no está formada, porque es para tres meses" (E3: Home, Contratado Posdoutoral).

Existe outra particulariedade no caso das investigadoras posdoutorais da Xunta de Galicia que son n(p)ais durante o contrato. Este é o caso dunha das nosas informantes. Ela si tivo dereito a prórroga pola baixa maternal, pero a cuestión a solventar administrativamente é como poder acceder ao contrato posdoutoral seguinte (Modalidade B da Xunta de Galicia). No seu caso, como o seu contrato vai rematar máis tarde que o das persoas da súa cohorte, vai ter que esperar uns meses no desemprego para poder voltar a presentarse á seguinte convocatoria. En definitiva, non só se trata de ofrecer prórrogas (que son imprescindíbeis), senon tamén de repensar como se poden encadear tales prórrogas coa continuidade da carreira investigadora.

Temos que ter en conta que a mencionada "peculiariedade" da carreira docente e investigadora pasa por unha estabilización laboral (no caso de que se dea) moi tardía. Así, é habitual que persoas con experiencia investigadora vaian encadeando contratos posdoutorais, con cargo a proxecto, ou prazas a tempo parcial coa esperanza de máis adiante sacar algún tipo de contrato ou praza estábel. A miúdo, a decisión de ter fillo/as se acaba pospoñendo, entrelazándose distinto tipo de atrancos: penalización por parte da administración, ausencia de redes familiares ou a intensidade horaria da investigación.

Todas estas variábeis fan realmente difícil para estas persoas que rondan os 3040 anos e que deciden ter crianzas, poder facelo nun ambiente medianamente estábel. Este conflito ás veces se resolve adiando a decisión para sempre. 
Noutras palabras, a precariedade fai que moitos "conflitos de conciliación" se resolvan sen ter crianzas.

Foron cinco as entrevistadas que comentaron de xeito explícito como o momento de ter fillos/as foi aprazado até ter certa estabilidade laboral. A seguinte informante explica o proceso de decisión de ter a súa filla cando tiña xa case 40 anos.

“Entrevistada: eso es difícil, y yo he tenido la ventaja de que mi marido trabaja aquí conmigo, ahí nos hemos podido turnar, sin perder..., del todo el trabajo, pero si, eso es difícil, lo que digo al margen de la encuesta, por ejemplo una cosa que es muy evidente en la gente de mi edad, en las áreas de ciencias, la cantidad de solteras que hay..., mujeres solteras, y si están casadas, muchas no tienen hijos, y si tienen hijos muchas solo tienen uno; y tardío... o sea yo lo tuve casi, iba a cumplir 40 años, porque hasta que te estabilizas, hasta que ves que puedes, que ya no tienes que mover... entonces...

E (entrevistadora): ¿tiene la sensación de que dejó algo apartado, de que perdió o sacrificó algo por su trabajo?

E: sí, el haber podido tener más hijos, o tenerlos antes, sí, tenerla antes (E14: Muller, Catedrática).

Relacionado tamén coa maternidade, pero esta vez no eido da docencia, outro dos temas fundamentais para o persoal docente é a consecución de sexenios. Unha das informantes,, nai de dúas crianzas, non acadou o último sexenio dada a carga de coidados que tivo que asumir nos últimos anos. A non consecución do sexenio supón unha sobrecarga ("intensificación”) de horas docentes, que no seu caso vai ser moi complexa de conciliar coa súa vida familiar. Hai que lembrar que segundo o Informe de datos da composición de mulleres e homes na Universidade de Vigo, no periodo 2009-2014, só o 38,8\% dos sexenios concedidos son a mulleres. 
O certo é que con respecto á docencia e á baixa maternal, outro dos nosos informantes sinala a necesidade de plantexar medidas de acción positiva, á vez que sinala que hai que evitar prácticas de "culpabilización" sobre as nais traballadoras que teñen que ser substituídas na docencia.

"Hai un tema fundamental que ten moito que ver coa promoción profesional, isto aínda non está claro, aquí hai que facer unha política clarísima de acción positiva, que nunca houbo, eh..., cómputo de horas dedicado á crianza, de como se valoran este tipo de cousas, medidas de acción positiva digamos de comparación entre curriculums masculinos e femininos, de eso, non hai na práctica, ¡nada! pero eso existe en moitas organizacións, xa, non? Ata que punto reglas de concursos, ou reglas de subsitucións, non? Como se pode favorecer a substitución á maternidade? En termos non únicamente de promoción de quen ten os fillos, senon a persoa que a substitúe, (...), aínda por riba, hai certo nivel de culpabilización do feito da maternidade nesta Universidade, porque crea un desaguisado nos departamentos" (E2: Home, Catedrático).

Por outra banda, dentro da carreira investigadora, existe a necesidade de realizar estadías longas no estranxeiro. No caso galego, o contrato posdoutoral que outorga a Xunta de Galicia obrígache a realizar unha estadía no estranxeiro durante dous anos, para posteriormente estabilizar un ano de contrato nalgunha Universidade galega. A esixencia de estadías de longa duración no estranxeiro posúe un claro nesgo de xénero, xa que como xa sabemos, as responsabilidades familiares adoitan recaer en maior medida sobre as mulleres, polo que esta esixencia resulta máis difícil de acadar para elas. Na investigación "Informe das traxectorias profesionais das mulleres na Universidade de Vigo" (2015), recolleuse a dificultade específica deste atranco para a promoción profesional das mulleres. Unha das informantes relata o parón que supuxo o feito de ter fillos/as na posibilidade de realizar estadías fóra.

Entrevistadora (E): fixeches algunha estadía? 
Entrevistada: si, este é un punto moi importante por unha razón, realizar unha estadía supón illarte no plano familiar, no plano social, en realidade ti vas fóra, a ter contacto con outra cultura, a outra Universidade, con outros métodos, para poder facer isto, tes que ter unha vida persoal e familiar moi ben organizada... na miña traxectoria é moi sintomático, eu fixen unha estadía antes de ser doutora e antes de ter fillos, e volvin facer estadías a partir de hai tres anos, é dicir, cando meus fillos xa tiñan unha certa autonomía; o salto vai de 1999 ata 2012, a min paréceme moi sintomático, eu podo sair unha semana, pero non podo sair un mes da miña casa... eso creo que é moi sintomático, eu creo que precisamente ese atranco non o ten nunca un home, teño compañeiros que se van de estadía un ano, que fan unha posdoc, teño de cooperación de Brasil, eu recibo colegas meus que veñen aquí por meses, e non importa, e son homes normalmente, esa é unha diferenza moi importante entre homes e mulleres no plano da investigación como atranco (E15: muller, Contratada Doutora).

No caso das estadías ao estranxeiro, unha ou outra opción, é dicir, marchar ou quedar, pode ser vivido como unha renuncia nalgunha das esferas, profesional ou persoal. Como comenta a seguinte entrevistada, unha das cousas que deixou apartada polo seu traballo é o tempo dedicado aos seus fillos.

“Entrevistadora (E): ¿tienes sensación de que dejaste algo apartado o que sacrificaste algo por tu trabajo?

Entrevistada: mis hijos

E: ¿En qué sentido?

Entrevistada: pues que les dediqué menos tiempo del que debía. O sea ahora a medida que, bueno, que ahora que los veo mayores, veo que me hubiera gustado disfrutarlos más, y los disfruté poco, ¿sabes?, o sea como que se me pasó su infancia" (E13: Muller, Titular). 
Todo apunta a que as pezas do crebacabezas non da encaixado para as mulleres académicas. A disxuntiva que deben enfrontar é a de adoptar unha estratexia masculinizada e competitiva, renunciando a unha vida persoal e familiar máis satisfactoria, ou ben tratar de sortear obstáculos para conciliar ambas esferas renunciando, previsíbelmente, ao éxito profesional (Kemelgor e Etzkowitz, 2001). En calquera caso, unha vez que deciden ser nais, a "ollada da sospeita" vai perseguilas ao longo da súa traxectoria profesional. Así, tres entrevistadas salientan os discursos discriminatorios aos que tiveron que facer fronte dada a súa situación familiar. Estes discursos apoiábanse na mesma idea: as mulleres deben relegar a súa carreira, a favor do coidado do seu marido ou fillos/as. Estes discuros proceden tanto de redes persoais, como do eido universitario, e non se circunscriben só ao pasado, senon que temos exemplos actuais deste tipo de discursos.

“Entrevistada: Houbo moito problema no departamento porque unha parte quería que a praza fose para un home, sen respectar ningún tipo de norma consuetudinaria (...) un membro do tribunal dixo que volvese pola praza despois de criar a miña filla" (E25: muller, Contratada Doutora).

A modo de síntesis, e tal e como sinalan González e Revelles (2017:1383), a perspectiva durante o ciclo vital desvela os problemas que sofren as mulleres durante a súa enteira traxectoria. Mostra que moitos dos acontecimentos importantes para a progresión científica (tese doutoral, mobilidade posdoutoral e primeiras posicións permanentes) emerxen dun cruce de camiños entre a formación dunha familia e a maternidade.

\subsection{Luces e sombras dos espazos para conciliar}

Para rematar coa exposición dos resultados cualitativos, examinarei os espazos de conciliación da UVigo, outra temática recurrente recollida no traballo de campo. 
O PDI entrevistado concorda na necesidade de determinados espazos para poder facilitar a conciliación. Das entrevistas realizadas en 2019 extráese un resultado clarificador: en catro entrevistas das cinco realizadas a mulleres que son nais traballadoras na UVigo, reclamouse a introducción das salas de lactancia para poder quitar o leite tras a reincoporación da baixa maternal. A partir da diagnose realizada, esta demanda foi recollida pola UVigo, que incorporou salas de lactancia nos tres campus universitarios.

Porén, segue existindo un grave problema co espazo de coidados a crianzas. Así, o 90\% das persoas entrevistadas que traballan no Campus de Vigo e teñen fillos/as, fixeron unha alusión directa á necesidade de crear unha escola infantil no campus de Vigo. A seguinte informante fai alusión á que a propia Universidade de Vigo dea exemplo no eido da conciliación, e aposte por unha escola infantil pública para o seu persoal.

“La universidad tendría que dar ejemplo, ¿cuántas personas están pidiendo una guardería? vamos a hacerla... ¡no! Pon la guardería, y luego ya las personas seguramente las van a usar, las que la están pidiendo y muchas otras, que una vez que la vean, digan, ¡ah! ¡Mira! Tiene que estar ahí, tiene que estar fja” (Contratada predoutoral, 38 anos).

A expansión de núcleos familiares asentados nunha cidade distinta da natal, sen redes familiares extensas, son algunhas das situacións familiares que nos atopamos entre as persoas PDI da UVigo. Unha das nosasinformantes, investigadora posdoutoral, pon o foco sobre a dificultade de conciliar os coidados da súa filla. Nun primeiro momento decidiron contratar a unha coidadora, pero na actualidade están pensando en meter á nena nunha gardería. Un dos problemas ten que ver con que o Campus de Vigo está alonxado da cidade, e isto supón unha dificultade engadida no caso de que a nena se 
enferme, xa que hai que ir buscala e pode demorar unha media horaEsta informante demanda que a administración pública asuma o seu papel para garantir a conciliación e facilite, neste caso, o traballo de coidados das crianzas.

\section{A COVID-19: O AFONDAMENTO DUNHA DESIGUALDADE PREVIAMENTE ANUNCIADA}

Dada esta diagnose previa de desigualdade en termos de conciliación entre o PDI: como impactou a pandemia e o confinamento na carga de traballo de coidados dos e das académicas? Que consecuencias diferenciais puido traer (e traerá) a pandemia nas carreiras profesionais do PDI?

Neste apartado examinaremos dous dos bloques de resultados máis relevantes da enquisa realizada en 2020 con PDI da UVigo: o bloque de coidados e o da produción científica.

Así, en primeiro lugar, no bloque de fenda de coidados, detectamos, na liña doutros estudos recentes como o da Unidad Mujeres y Ciencia (2020) que as variacións entre homes e mulleres académicas son significativas. Antes do estado de alarma as mulleres son as coidadoras principais $(21,3 \%)$ e apenas o $5 \%$ dos homes indica asumir a responsabilidade de maneira central. Cando se establece o estado de alarma, o 14 de marzo de 2020, aumenta a carga das mulleres e máis do 50\% con menores de 12 anos atenden en exclusiva aos fillos / as, porcentaxe que se queda no $17 \%$ dos homes.

En xeral conciliar o traballo remoto coa vida laboral e familiar resultou unha tarefa difícil ou moi difícil para o 60\% das persoas enquisadas; sendo moi difícil para o $17,4 \%$ das mulleres e para o $7,1 \%$ dos homes. Na categoría "difícil" acumúlase a o maior volume de resposta: o 51,6\% de homes e o 44,3\% das mulleres.

Relacionado con isto, os datos da enquisa corroboran o recollido nos estudos cualitativos citados anteriormente, e se fai patente a feminización do traballo doméstico que evidencia unha desigual carga das responsabilidades nos fogares. Da ampla batería de actividades vinculadas coas tarefas de coidados e xestión do fogar as mulleres asumen maioritariamente todas elas a excepción da 
compra presencial e as actividades de bricolaxe e xardinería. Esta enquisa mostra que a fenda de xénero se acentúa naquelas tarefas máis exixentes como a xestión en xeral do fogar $(64,4 \%)$, a ordenación de armarios $(63,1 \%)$, o lavado e a desinfección de roupa, limpeza en xeral do fogar, limpeza do baño ou preparación da comida $(50,3 \%)$.

En definitiva, a desigualdade de responsabilidades asumidas afecta na dispoñibilidade do tempo para a vida persoal e os autocoidados, e as mulleres ven penalizado o seu tempo de descanso durante o estado de alarma de forma significativa. Cinco de cada dez mulleres enquisadas afirman non dispor de tempo para elas, diminuíndo ata quince puntos no caso dos homes $(34,9 \%)$.

Con respecto ao bloque de produción científica, no tempo que durou o estado de alarma a actividade investigadora redúcese e só o 65,8\% das persoas enquisadas dedicou tempo á revisión e envío de artigos. As persoas que non dedicaron tempo adoecen á carga docente e a dificultades para conciliar como causas centrais. Neste senso, a fenda de xénero resulta evidente á hora de analizar o tempo dedicado á revisión de artigos e publicacións durante a duración do estado de alarma: os homes manteñen esta activade investigadora nun $75 \%$ dos casos, mentres que a porcentaxe de mulleres redúcese ao 58,6\%, alegando maiores dificultades por atender ao traballo docente, as tarefas de conciliación e ver diminuída a súa capacidade de concentración.

Durante o estado de alarma resultan máis evidentes as diferenzas entre mulleres e homes no que respecta ao volume de artigos ou outras publicacións enviadas. Mentres os homes indican ter traballado nunha media de 2,24 publicacións de carácter internacional e 1,74 nacional, as mulleres envían unha media de 2,06 publicación internacionais e de 1,65 nas nacionais. Entre as PDI con fillas e fillos menores de 12 anos a media é mais baixa (1,98 internacionais e 1,39 nacionais) que entre o grupo sen fillos/as menores $(2,22$ e 1,86 respectivamente).

Por outra banda, relacionado coa actividade investigadora, durante o periodo do estado de alarma tan só solicitan proxectos o 14,3\% das persoas investigadoras, sendo máis homes $(18,3 \%)$ que mulleres $(11,3 \%)$. 
A valoración en termos xerais que fan o persoal PDI enquisado respecto do nivel de actividade investigadora durante o estado de alarma é que esta veuse afectada negativamente, reducíndose para cinco de cada dez enquisado/as. As mulleres indican un maior impacto da actividade investigadora e mesmo o $33,8 \%$ sinala que diminuíu considerablemente. En cambio, o impacto na actividade investigadora dos homes sendo tamén importante resultou máis atenuado e so o $16 \%$ di ter diminuído considerablemente.

Gráfico 1. Variación da actividade investigadora durante o estado de alarma segundo sexo. Datos en porcentaxe.

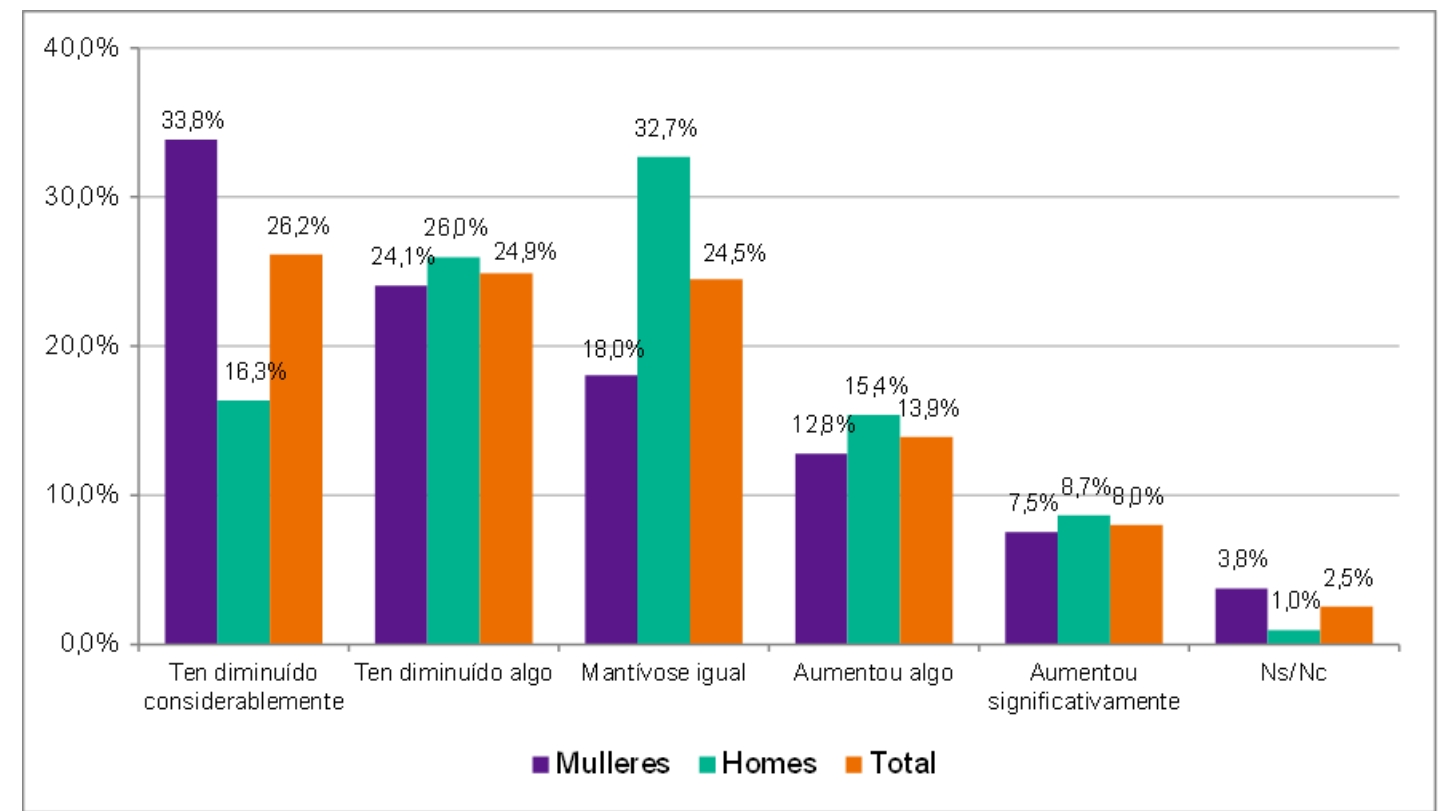

Fonte: Enquisa do Proxecto (omisión por anonimato). Base: Persoas que desenvolveron actividade científica no último ano (Mulleres: 133, Homes: 104, Total: 237).

\section{CONCLUSIÓNS. DA FENDA DE COIDADOS Á FENDA DE INVESTIGACIÓN}

Este artigo comezou cunha explotación de datos cualitativos procedentes de dous proxectos de investigación da Unidade de Igualdade da UVigo. A través dos discursos das persoas entrevistadas detectamos unha tensión clara entre a dedicación a súa profesión e o coidado de fillos ou fillas e outros/as familiares. Unha xestión dos tempos que se complexiza máis para as mulleres PDI. Estas 
académicas se moven entre dúas institucións voraces que demandan, ao mesmo tempo e sen tregua, unha lealtade global: o traballo e a familia (Acker, 1994). As Universidades, a pesares dos planes de igualdade, teñen moito traballo por diante para acadar maiores cotas de corresponsabilidade e igualdade de xénero. As xornadas vespertinas, a falla de transparencia nos horarios e a penalización da maternidade na carreira profesional son, a día de hoxe, algunhas das barreiras máis relevantes.

Estes resultados poñen de manifesto unha desigualdade evidente entre homes e mulleres académicas, unha desigualdade que se viu claramente intensificada co impacto da pandemia da Covid-19.

A cantidade desproporcionada de traballo doméstico e de coidados asumido polas mulleres evidenciase, segundo a enquisa examinada, aínda máis nas investigadoras con fillas e fillos menores. A feminización das actividades de coidados e domésticas acentuouse no confinamento e as mulleres asumiron aínda máis carga de traballo, intensificada pola atención, no seu caso, de coidados a persoas dependentes e menores e nas actividades de apoio educativo. Esta fenda de coidados traduciuse, como detallamos a través da enquisa, en fenda de investigación. Os resultados a curto prazo fanse evidentes, pero teremos que agardar novos estudos para verificar o alcance deste repunte da desigualdade, e os seus efectos a medio e longo prazo nas universidades e na actividade investigadora.

Outros estudos internacionais coinciden cos resultados da enquisa realizada na UVigo, e mostran unha "fenda de xénero nas publicacións académicas" durante a pandemia. Recentemente, unha reportaxe de Giuliana Viglione para a revista Nature (2020) mostraba que os datos preliminares que se están a recoller en diferentes contextos e disciplinas indican que as mulleres están enviando menos 
artigos para publicar e comezando menos proxectos de investigación que os seus colegas varóns. Por exemplo, os arquivos de repositario consultados en disciplinas como as ciencias físicas indican que considerando o período abrilmaio do ano 2019 e comparándoo co mesmo período do ano 2020, as mulleres teñen incremetado os seus envíos de artigos nun 2,7\%, mentres que os varones teñen incrementado os seus envíos nun $6,4 \%$.

A fotografía que fun detallando ao longo destas páxinas deixa claro que a corresponsabilidade é unha utopía aínda lonxana nun eido universitario onde se asenta a precariedade e a sanción á traxectoria profesional cara as académicas con responsabilidades familiares. Unha fotografía que empeora coa situación de pandemia. Porén, os obstáculos que enfrontan as mulleres non só se reducen ás difíciles posibilidades reais de conciliación, senon aos discursos discriminatorios de xénero nun contexto de poder masculino. As dinámicas patriarcais continúan presentes na Universidade, freando o avance profesional de moitas académicas, tamén para as que non teñen descendencia. Tomàs e Guillamón (2009) chegan a conclusións semellantes en investigacións en contextos universitarios, onde os colegas masculinos se mostran convencidos de que a necesidade de consolidar unha carreira profesional é máis forte nun home que nunha muller, xogando estes prexuízos unha sorte de profecía autocumprida, onde os varóns con poder toman decisións que favorecen a promoción doutros varóns fronte ás mulleres. $\mathrm{O}$ androcentrismo nas Universidades fai que a produción científica quede en mans dalgúns e continúe coa invisibilidade das científicas e das profesoras universitarias (González, 2018).

Supón un reto para as Universidades facer fronte a estas desigualdades que se están a reproducir e intensificar nos último ano, mostrando con toda a súa crudeza o conflito capital-vida, mediado por esa cultura patriarcal da 
institución universitaria. Desde os feminismos temos o temor (real) de que as situacións de crise afonden nas desigualdades entre homes e mulleres: isto nos debe facer estar alerta nas diagnoses, e elaborar propostas que subvirtan as fendas de xénero asentadas no eido universitario e científico.

\section{BIBLIOGRAFÍA}

Acker, S. (1995). Género y educación. Madrid: Narcea.

Balbo, L. (1982). Volvamos a hablar del Estado del Bienestar: la sociedad asistencial, la sociedad de los servicios, la sociedad de la crisis. Papers, 18, 51-85, doi: https: / / doi.org/10.5565/rev/papers/v18n0.1324

Benería, L. (1979). Reproduction, production and the sexual division of labour. Cambridge Journal of Economics, 3 (3), 203-225. doi: https:/ / doi.org/10.1093/oxfordjournals.cje.a035421

Bock, G. (1993). Pobreza femenina, derechos de las madres y Estados del bienestar (1890-1950). En G. Duby e M. Perrot, Historia de las mujeres. El siglo XX (pp. 438-478). Madrid: Santillana.

Borderías, C., Carrasco, C. e Alemany, C. (comp.) (1994). Las mujeres y el trabajo: rupturas conceptuales. Barcelona: Icaria.

Blahopoulou, J. (2015). La conciliación de la vida laboral, familiar y personal en tiempos de crisis. Palma: Edicions UIB.

Carrasco, C. (2006). La paradoja del cuidado: necesario pero invisible. Revista de Economía Crítica, 5, 39-64.

Carrasco, C., Borderías, C. e Torns, T. (eds.). El trabajo de cuidados. Historia, teoría y políticas. Madrid: Catarata.

Casado, E. e Gómez, C. (eds) (2006). Los desafíos de la conciliación de la vida familiar y profesional en el siglo XXI. Madrid: Editorial Biblioteca Nueva.

Delphy, C. (1980). Por un feminismo materialista. El enemigo principal y otros textos. Barcelona: La Sal- Cuadernos inacabados.

Díez, E.J. (2017). Precariado Universitario (27 de Marzo de 2017). Recuperado de https://www.nuevatribuna.es/opinion/enrique-javier-diezgutierrez / precariado-universitario/20170327101647138077.html.

Instituto Nacional de Estadística (INE) (2009-2010). Enquisa de Emprego do Tempo 2009-2010. Madrid: Instituto Nacional de Estadística.

Esping-Andersen, G. (1993). Los tres mundos del Estado del Bienestar. Valencia: Alfons el Magnánim. 
Finch, J. e Groves, D. (1983). Labour and love: women, work and caring. London: Routledge e Kegan Paul.

Folbre, N. (1995). Holding hands at midnight: the paradox of caring labor. Feminist Economics, 1 (1), 73-92. doi: https:/ / doi.org/10.1080/714042215

Gómez, A., Vázquez, I. e Cidadanía (2020). Xénero e investigación científica en tempos da Covid-19. Vigo: Unidade de Igualdade, Universidade de Vigo.

González, A. M. (2018). Mujeres en la ciencia contemporánea. La aguja y el camello. Barcelona: Icaria.

González, A. M. e Revelles, B. (2017). Excelencia en la ciencia: una reflexión crítica afirmativa, Cadernos de Pesquisa, 47 (166), 1372-1394. doi: https:// doi.org/10.1590/198053144233

Kemelgor, C. e Etzkowitz, H. (2001). Overcoming isolation: Women's dilemmas in American Academic Science, Minerva, 39, 239-257. doi: https://doi.org/10.1023/A:1010344929577

Lei Orgánica 3/2007, de 22 de marzo, para a igualdade efectiva de mulleres e homes, BOE núm. 71, de 23 de marzo de 2007.

Moreno, L. (2002). Bienestar mediterráneo y 'supermujeres'. Revista Española de Sociología, Revista Española de Sociología, 2, 41-56.

Pérez Orozco, A. (2006). Amenaza tormenta: la crisis de los cuidados y la reorganización del sistema económico. Revista de Economía Crítica, 5, 737.

Pérez-Caramés, A. (2010). Configuraciones del trabajo de cuidados en el entorno familiar. De la toma de decisión a la gestión del cuidado. Alternativas. Cuadernos de trabajo social, 17, 121-140. doi: https:/ / doi.org/10.14198/ALTERN2010.17.7

Rivero, A. (dir.) (2008). De la conciliación a la corresponsabilidad: buenas prácticas y recomendaciones. Madrid: Instituto de la Mujer.

Sapir, A. (2005). Globalisation and the Reform of European Social Models. Bruselas: Bruegel Policy Brief.

Saraceno, C. (1980). Il lavoro mal diviso. Bari: De Donato.

Standing, G. (2013). Precariado. Una nueva clase social. Barcelona: Pasado y Presente.

Tomàs, M. e Guillamón, C. (2009). Las barreras y los obstáculos en el acceso de las profesoras universitarias a los cargos de gestión académica. Revista de educación, 350, 253-275.

Unidad de Mujeres y Ciencia (UMYC) (2020). Resultados del cuestionario sobre el impacto del confinamiento en el personal investigador, FECYT. Dispoñible en: https: / / www.ciencia.gob.es/stfls / MICINN/Ministerio/FICHEROS/R 
esultados_cuestionario_impacto_confinamiento_personal_investigador _UMyC.pdf (consulta: 10/10/2020).

Unidade de Igualdade, Universidade de Vigo (2015). Informe análise das traxectorias profesionais das mulleres na Universidade de Vigo. Recuperado de: https://www.uvigo.gal/opencms/export/sites/uvigo/sites/default/u vigo/DOCUMENTOS/igualdade/ANL_INFORME_TRAXECTORIAS_ PROFESIONAIS_completo_ITCBaskerville.pdf (consulta: 01/03/2019).

Unidade de Igualdade, Universidade de Vigo (2015). Informe de datos da composición de mulleres e homes na Universidade de Vigo (2009-2014). Recuperado https://www.uvigo.gal/opencms/export/sites/uvigo/sites/default/u vigo/DOCUMENTOS/igualdade/Informe_da_composicixn_de_muller es_e_homes_da_Uvigo_maio_2015_.pdf (consulta: 01/03/2019).

Viglione, G. (2020). Are women publishing less during the pandemic? Here's what the data say. Nature, 581, 365-366. doi: https: / / doi.org/10.1038/ d41586-020-01294-9

Xarxa Vives (2019). El biaix de gènere en el reclutament, la promoció i la retenció del personal a les universitats. Castelló de la Plana: Xarxa Vives. 